\title{
Relationship of physical activity and dietary habits with body mass index in the transition from childhood to adolescence: a 4 -year longitudinal study
}

\author{
Leen Haerens ${ }^{1,2, *}$, Carine Vereecken ${ }^{1,3}$, Lea Maes ${ }^{3}$ and Ilse De Bourdeaudhuij ${ }^{2}$ \\ 'Research-Foundation Flanders: ${ }^{2}$ Department of Movement and Sports Sciences, Ghent University, \\ Watersportlaan 2, 9000 Gent, Belgium: ${ }^{3}$ Department of Public Health, Ghent University, De Pintelaan 185, \\ BLOK A, 9000 Gent, Belgium
}

Submitted February 2009: Accepted May 2010

\begin{abstract}
Objective: To explore the relationship between several physical activity (PA) and dietary behaviours and BMI $Z$-score and to investigate the relationship between changes in these variables and in the BMI $Z$-score over a 4 -year period from childhood to adolescence.

Design: Longitudinal study in which children were included in the fifth grade and measured for four consecutive years. Dietary and PA behaviours as well as height and weight were measured by means of self-reported validated questionnaires. Setting: Fifty-nine Flemish elementary schools.

Subjects: The baseline sample consisted of $51.9 \%$ boys and the mean age was 10 (SD 0.4) years. During the first measurement year (2002), data on 1670 fifth graders were gathered. These measurements were repeated after 1 ( $n$ 1557), 2 ( $n$ 1151) and $3(n$ 807) years.

Results: Significant inverse relationships with BMI $Z$-score were observed for frequency of breakfast consumption $(\beta=-0 \cdot 033, \mathrm{sE}=0 \cdot 012)$ and frequency of sports participation $(\beta=-0 \cdot 011, \mathrm{SE}=0 \cdot 004)$ across four time points. Significant inverse relationships between changes in BMI $Z$-score and changes in frequency of sports participation $(\beta=-0 \cdot 011, \quad \mathrm{SE}=0 \cdot 006)$ and hours of physical education (PE; $\beta=-0.052$, $\mathrm{sE}=0 \cdot 023$ ) were observed, meaning that decreases in sports participation and hours spent in PE were associated with increases in BMI $Z$-score.

Conclusions: The present study provides an important insight into different dietary and PA behaviours related to (changes in) BMI $Z$-score during the transition from childhood to adolescence.
\end{abstract}

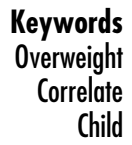

The increase in overweight and obesity levels in the past decades shows an urgent need for a better understanding of its causes across the lifespan ${ }^{(1)}$. Research on balancing energy intake and expenditure through adequate nutrition and physical activity (PA) habits can be considered as a primary focus in this understanding ${ }^{(2)}$. Minor changes in food intake and PA can have sizeable effects on body weight and obesity ${ }^{(3)}$. However, it is less clear which specific diet and PA patterns contribute to the risk of weight gain in specific populations.

A crucial age when children are at increased risk for unnecessary weight gain is the transition from childhood to adolescence ${ }^{(4-6)}$. At the age of 10-12 years, children get more decision-making power about what they eat and how they spend their leisure time. This transition was found to be a critical period for several energy-related behaviours: skipping breakfast, dropout from sports clubs, increase of computer use, increase of snacking and soft drink consumption ${ }^{(7-8)}$. Most previous studies in this age group used cross-sectional data based on a singlemoment measurement to show a relationship between nutrition or PA habits and overweight status or BMI. Despite the merits of these designs, longitudinal data are urgently needed to get better insight into the relationships of nutrition and PA with weight gain over time ${ }^{(9)}$. Moreover, previous studies seldom combined PA and nutrition habits in their relationship with $\mathrm{BMI}^{(10-11)}$. Combining both energy balance-related behaviours is however crucial in understanding their mutual relationship in explaining weight gain. In addition, it is not clear whether total energy intake and activity levels or, in contrast, more specific nutrition and PA behaviours, such as eating breakfast, drinking soft drinks, watching television, participating in sports, contribute most to weight gain in the transition from childhood to adolescence ${ }^{(12-14)}$.

The aim of the present study was therefore to explore (i) the relationship between several PA and dietary behaviours and BMI $Z$-score and (ii) the relationship of 
changes in these PA and dietary behaviours with changes in BMI $Z$-score over a 4 -year period from childhood to adolescence.

It is hypothesized that healthy dietary behaviours (e.g. frequent breakfast, fruit and vegetable consumption) and increased PA levels will contribute to less weight gain, whereas unhealthy dietary habits, such as frequent soft drink and sweets consumption, will be related to more weight gain.

\section{Methods}

\section{Procedure}

A longitudinal study in which children were included in the fifth grade and measured for four consecutive years was used - the Longitudinal Eating and Activity study. In 2002, 100 elementary schools from two Flemish regions were randomly selected from the official list of the Flemish government. The principals were sent a recruitment letter and later contacted by phone. There were fifty-nine principals who agreed to cooperate in the study. All children in the fifth grade (10-year-olds) in these fifty-nine schools were invited to participate in the study ( $n$ 1957). Informed consent to participate in the longitudinal study was received from 1725 parents (88.1\% of eligible children). In October-December 2002 (T1), the children completed a self-administered questionnaire on eating habits and PA, demographic variables and possible psychosocial determinants in the classroom under the supervision of one researcher and their classroom teacher. Questionnaires of 1670 children were gathered, of which 1270 contained all the information needed for the analyses in the present study. One year later, in the fall of 2003 (T2), this procedure was repeated and the same children were asked again to fill in the questionnaire in the classroom. In total, 1557 valid questionnaires were gathered, of which 1066 contained all the information needed for the analyses in the present study. Not participating was caused by moving, changing school or being absent on the day of administration. In 2004, all children had left primary school and entered different secondary schools making classroom-based administration of questionnaires impossible. In the fall of 2004, the children were contacted by sending a letter to their home addresses (T3). The envelope contained two letters: one was addressed to the parents asking them to encourage their children to participate in the study; and the other was addressed to the child containing a login and password and asking him or her to complete the Webbased questionnaire online. As this procedure did not give the response rate we hoped (only about $30 \%$ ), a second envelope was sent 8 weeks later to the home addresses of those who had not filled in the online questionnaire. This reminder also included the paper questionnaire and a prestamped envelope to send the questionnaire back with the regular mail. In total, 1151 questionnaires were received in this wave, of which 791 contained all the information needed for the analyses in the present study. In 2005, the same procedure was repeated. At T4, a total of 807 children completed the questionnaire, of which 585 contained all the information needed for the analyses in the present study. The main reasons for not participating at T3 and T4 were inability to be reached (not living at the address anymore) and not able (online) or willing (paper) to fill in the questionnaire. Ethical approval was received from the Ghent University.

\section{Sample}

The sample at T1 consisted of $51.9 \%$ boys. The mean age was $10\left(\right.$ sD 0.4 ) years, mean BMI was $16.5($ sD 2.5$) \mathrm{kg} / \mathrm{m}^{2}$ and $98 \%$ had a Belgian nationality. Dropout analyses were executed to look at baseline differences between those who stayed in the study over each of the 4 years compared with those who dropped out.

At T2, no differences were found for gender, socioeconomic status (SES), nationality, fruit and vegetable consumption, soft drink consumption, frequency of breakfast consumption, frequency and duration of sports participation and active transport. Significant differences were found for age, BMI $Z$-score, consumption of sweets and hours of physical education (PE). Children who dropped out at T2 were somewhat older $(P<0 \cdot 001)$, had lower BMI $Z$-scores $(P=0 \cdot 016)$, consumed fewer sweets $(P=0 \cdot 018)$ and engaged in fewer hours of PE $(P=0 \cdot 04)$.

At T3, no differences were found for gender, fruit and vegetable consumption, sweets and soft drink consumption, frequency and duration of sports participation, hours of PE and active transport. Significant differences were found for SES, nationality, age and frequency of breakfast consumption. Children who dropped out at T3 were somewhat older $(P<0 \cdot 001)$ and consumed breakfast less frequently $(P=$ $0 \cdot 030$ ). In addition, the percentages of students who dropped out were higher among children with parents with no higher education or with a foreign nationality.

At T4, no differences were found for gender, BMI $Z$-score, fruit consumption, sweets, frequency and duration of sports participation, hours of PE and active transport. Significant differences were found for age, SES, vegetable intake and breakfast consumption. The children who dropped out were somewhat older $(P<0 \cdot 001)$, consumed more soft drinks $(P=0 \cdot 013)$, ate fewer vegetables $(P=0 \cdot 010)$, ate breakfast less frequently $(P=0 \cdot 016)$ and had a somewhat higher BMI $(P=0 \cdot 001)$. In addition, the percentages of students who dropped out were higher among children with parents with no higher education or with a foreign nationality.

\section{Measures}

\section{Dietary habits}

Dietary habits were operationalized as the consumption of breakfast, fruit, vegetables, soft drinks and sweets. 
The consumption of fruit and vegetables is important in reducing the risk of cancer and $\mathrm{CVD}^{(15-18)}$. The consumption of sweets and soft drinks can impede the intake of more nutritious foods by reducing appetite control ${ }^{(12)}$. The daily intake of breakfast is important for the nutritional status of schoolchildren and reduces their risk for future heart disease ${ }^{(19-21)}$. The daily use of breakfast is also a crude measure of the regularity of meal consumption and has an important impact on dietary adequacy ${ }^{(22,23)}$.

Respondents were asked to assess the frequency of consumption of the food items - in terms of $\mathrm{d} /$ week (FFQ). Response categories were 'never', '< $1 \mathrm{~d} /$ week', ' $1 \mathrm{~d} /$ week', '2-4d/week', '5-6d/week', 'once a day', 'every day' and 'every day more than once'. This FFQ has sufficient reliability and validity to be useful for ranking subjects ${ }^{(24)}$. To assess the consumption of breakfast, the respondents were asked to tick how many days in a week and in a weekend they had breakfast. Response categories were 'never,' ' $1 \mathrm{~d}$ ', ' $2 \mathrm{~d}$ (so far the categories for weekends)', ' $3 \mathrm{~d}$ ', ' $4 \mathrm{~d}$ ' and ' $5 \mathrm{~d}$ '. A composite measure was created that added up the number of days that the respondents had breakfast.

\section{Activity babits}

Activity habits were operationalized as duration of active transportation to school, frequency and duration of sports participation and duration of PE at school.

Active transportation was assessed by asking for the $\mathrm{min} / \mathrm{d}$ respondents walked or cycled to and from school. To assess sports participation, the respondents reported their two main sports with the frequency and duration (h/week) of participation. Responses for the frequency were reported on a 10-point scale ranging from 'less than two times a month to every day more than once'. Duration was reported in h/week. A composite measure was created, adding up the two sports. The respondents also reported the hours of (obligatory) PE they had at school, ranging from 0 to $7 \mathrm{~h}$ /week.

Questions were derived from the validated Flemish Physical Activity Questionnaire ${ }^{(25)}$ and also used in previous research assessing PA among adolescents ${ }^{(26,27)}$.

\section{BMI and demographic variables}

Self-reported weight and height were used to calculate BMI $\left(\mathrm{kg} / \mathrm{m}^{2}\right)$. BMI $Z$-scores were calculated on the basis of the Flemish reference data ${ }^{(28)}$ using the least mean square method $^{(29,30)}$. A $Z$-score is the number of standard deviation units that a person's BMI has deviated from the mean or reference value. Therefore, a positive change in $Z$-score indicates an increase in relative BMI, and a negative change indicates a decrease in relative BMI. Parental education level was used as a proxy for SES. The highest level of education of the mother and father was dummy coded as 0 (no higher education) and 1 (degree of higher education). Gender was dummy coded with 0 (girls) and 1 (boys) ${ }^{(31)}$.

\section{Statistical analyses}

A three-level hierarchical multi-level model (school/pupil/ measurement) was created to investigate the relationships between dietary and PA behaviours and BMI $Z$-score. Pearson's correlations were executed to investigate the possible problems of multi-collinearity among explanatory variables before they were included in the model (see Table 1).

Two sets of models were conducted. All explanatory variables were mean centred before they were entered in the models. To examine the multivariate relationships of all of the PA and dietary behaviours with BMI $Z$-score, multi-level regression analyses were conducted by regressing all behavioural determinants onto the BMI $Z$-score, controlling for time, gender and SES (model 1). The following dietary behaviours were included in the models: frequency of breakfast, fruit, vegetable, soft drink and sweets consumption. For PA, the following variables were included: frequency of sports participation, h/week of sports participation, time spent in active transportation to school and hours of PE.

The same model was repeated by regressing changes in the behavioural determinants onto changes in the BMI $Z$-score. Changes were calculated by means of residual change scores. For example, a measure of 'change of BMI $Z$-score' between pre- and post-test free of autocorrelated error was created by regressing the BMI $Z$-score measures at post-test onto the measures at baseline to compute the residualized BMI $Z$-score change index (the difference between the predicted and observed BMI Z-score at posttest). The resulting residualized scores can be interpreted as the amount of increase or decrease in BMI $Z$-score

Table 1 Correlations $(r)$ between independent variables included in the multi-level models $(n$ 3716)

\begin{tabular}{|c|c|c|c|c|c|c|c|c|}
\hline & Breakfast & Fruit & Vegetables & Sweets & $\begin{array}{c}\text { Soft } \\
\text { drinks }\end{array}$ & $\begin{array}{l}\text { Sports participation } \\
\text { (frequency) }\end{array}$ & $\begin{array}{l}\text { Sports participation } \\
\text { (duration) }\end{array}$ & $\begin{array}{l}\text { Hours } \\
\text { of PE }\end{array}$ \\
\hline Fruit & $0 \cdot 12$ & 1 & & & & & & \\
\hline Vegetables & $0 \cdot 13$ & 0.23 & 1 & & & & & \\
\hline Sweets & -0.03 & -0.02 & $-0 \cdot 01$ & 1 & & & & \\
\hline Soft drinks & $-0 \cdot 13$ & $-0 \cdot 14$ & $-0 \cdot 11$ & 0.33 & 1 & & & \\
\hline Sports participation (frequency) & 0.02 & 0.09 & 0.02 & -0.01 & -0.01 & 1 & & \\
\hline Sports participation (duration) & $-0 \cdot 01$ & 0.04 & 0.03 & -0.03 & -0.01 & 0.58 & 1 & \\
\hline Hours of PE & 0.02 & -0.00 & 0.06 & 0.03 & -0.02 & -0.02 & -0.04 & 1 \\
\hline Active transportation & -0.01 & -0.02 & 0.05 & 0.00 & -0.03 & 0.04 & 0.02 & 0.07 \\
\hline
\end{tabular}

PE, physical education. 
Table 2 Unstandardized and standardized regression coefficients for the relationships between dietary and physical activity behaviours and BMI Z-score

\begin{tabular}{|c|c|c|c|c|c|c|}
\hline & \multicolumn{3}{|c|}{$\begin{array}{l}\text { Model } 1 \\
(n \text { 3716) }\end{array}$} & \multicolumn{3}{|c|}{$\begin{array}{l}\text { Model } 2 \\
(n \text { 2033) }\end{array}$} \\
\hline & $\beta$ (unstandardized) & SE & $\beta$ (standardized) & $\beta$ (unstandardized) & SE & $\beta$ (standardized) \\
\hline \multicolumn{7}{|l|}{ Fixed part } \\
\hline Time & $0.060^{\star \star \star}$ & $0 \cdot 011$ & - & -0.008 & 0.022 & - \\
\hline Gender & -0.061 & 0.052 & - & -0.045 & 0.035 & - \\
\hline SES & $-0 \cdot 109$ & 0.080 & - & 0.073 & 0.055 & - \\
\hline & $-0 \cdot 148^{*}$ & 0.073 & - & -0.008 & $0 \cdot 050$ & - \\
\hline \multicolumn{7}{|l|}{ Frequency } \\
\hline Breakfast & $-0.033^{* *}$ & 0.012 & $-0.039^{\star *}$ & -0.022 & 0.016 & -0.031 \\
\hline Fruit & -0.016 & $0 \cdot 011$ & -0.023 & -0.022 & 0.014 & -0.037 \\
\hline Vegetables & -0.009 & $0 \cdot 013$ & -0.010 & -0.015 & $0 \cdot 018$ & -0.019 \\
\hline Sweets & -0.009 & $0 \cdot 010$ & -0.013 & -0.000 & 0.013 & 0.000 \\
\hline Soft drinks & -0.016 & 0.009 & -0.029 & -0.009 & $0 \cdot 011$ & -0.018 \\
\hline Sports participation & $-0 \cdot 011^{* *}$ & 0.004 & $-0 \cdot 040^{\star \star \star}$ & $-0 \cdot 011\left(^{*}\right)$ & 0.006 & $-0 \cdot 051^{\star \star *}$ \\
\hline \multicolumn{7}{|l|}{ Duration (h/week) } \\
\hline Sports participation & -0.005 & 0.004 & -0.020 & -0.006 & 0.005 & -0.033 \\
\hline Hours of PE & -0.012 & 0.018 & -0.008 & $-0.052^{*}$ & 0.023 & -0.005 \\
\hline \multicolumn{7}{|l|}{ Duration (min/week) } \\
\hline \multirow[t]{2}{*}{ Active transportation to school } & -0.000 & $0 \cdot 001$ & $0 \cdot 000$ & $-0 \cdot 000$ & $0 \cdot 001$ & $0 \cdot 000$ \\
\hline & $\sigma^{2}$ & SE & & $\sigma^{2}$ & SE & \\
\hline \multicolumn{7}{|l|}{ Random part null model } \\
\hline School-level variance & 0.014 & 0.012 & & 0.000 & 0.000 & \\
\hline Pupil-level variance & $0 \cdot 766^{\star \star \star}$ & 0.037 & & 0.000 & 0.000 & \\
\hline Measurement-level variance & $0 \cdot 397^{\star \star \star}$ & $0 \cdot 012$ & & $0.584^{\star \star \star}$ & $0 \cdot 018$ & \\
\hline \multicolumn{7}{|l|}{ Random part full model } \\
\hline School-level variance & 0.014 & 0.012 & & 0.000 & 0.000 & \\
\hline Pupil-level variance & $0 \cdot 743^{\star \star \star}$ & 0.036 & & 0.000 & 0.000 & \\
\hline Measurement-level variance & $0 \cdot 398^{\star \star \star}$ & 0.012 & & $0.576^{\star \star \star}$ & 0.018 & \\
\hline
\end{tabular}

SES, socio-economic status; PE, physical education.

Model 1: Multivariate model adjusted for all explanatory variables, controlling for time, gender and SES.

Model 2: Multivariate model using residual change scores adjusted for all other variables.

For the random part of the null model only demographic variables are included; for the random part of the full model all variables were included.

( $) P<0.07 ;{ }^{\star} P<0.05 ;{ }^{\star \star} P<0.01 ;{ }^{* \star} P<0.001$.

between baseline and post-test, independent of the baseline BMI $Z$-score. The same procedure was followed for all predictor variables.

To allow for relative comparisons of strength between the observed relationships, standardized $\beta$-coefficients were calculated by means of the following formula [(unstandardized $\beta) \times(\mathrm{sD}$ explanatory variable $)] /(\mathrm{SD}$ outcome variable)]. These standardized $\beta$-coefficients can be interpreted as the amount of change in the BMI Z-score associated with a 1 SD change in the predictor variable. To get estimates of the proportion of between-pupil variance (level 2) explained by each of the predictor variables, the proportion of unexplained variance of the full model was compared with the model including only the constant and the sociodemographic covariates.

All analyses were conducted using MLwiN version $2 \cdot 12$ (Centre for Multilevel Modelling, University of Bristol, UK). $P$ values of 0.05 were considered as significant.

\section{Results}

Table 2 presents the unstandardized and standardized regression coefficients for the first model. In the first model, a significant inverse relationship with BMI $Z$-score was observed for frequency of breakfast consumption $(\beta=-0 \cdot 033, \mathrm{SE}=0 \cdot 012)$ and frequency of sports participation $(\beta=-0 \cdot 011, \mathrm{sE}=0 \cdot 004)$ across four time points. Breakfast consumption explained $0.7 \%$ of the betweenpupil variance in BMI $Z$-score. Frequency of sports participation explained $1 \cdot 2 \%$ of the between-pupil variance in BMI Z-score. The decrease in pupil-level variance from the null model (only including covariates) to model 1 (including all explanatory variables) shows that $3 \%$ of the between-pupil variance in BMI $Z$-score is explained by the explanatory behavioural variables. Variance at the school level was not significant $(Z=1 \cdot 2)$ with $0 \cdot 8 \%$ of the variance in BMI $Z$-score explained at the school level. Variance at the individual level was highly significant ( $Z=20 \cdot 7, P<0 \cdot 001$ ) with $65 \cdot 1 \%$ of the variance in BMI $Z$-score explained at the individual level.

Table 2 also presents the unstandardized and standardized regression coefficients for the second model. In the second model, a significant inverse relationship was found between changes in hours of PE $(\beta=-0 \cdot 052$, $\mathrm{SE}=0.023)$ and BMI $Z$-score, meaning that decreases in hours spent in PE were associated with increases in BMI $Z$-score. In addition, a trend for a significant relationship 
$(\beta=-0 \cdot 011, \quad \mathrm{SE}=0 \cdot 006)$ between changes in sports participation and changes in BMI $Z$-score was observed, meaning that increases in sports participation were related to decreases in BMI $Z$-score.

\section{Discussion}

The first purpose of the present study was to explore the relationship of a range of PA and dietary behaviours with BMI $Z$-score across a 4 -year period from childhood to adolescence. For most of the dietary behaviours included in the present study, no significant relationships with BMI $Z$-score were found. In accordance with the results of the present study, a recent review ${ }^{(32)}$ found no evidence for an association between fruit and vegetable consumption and BMI among children and adolescents. On the other hand, most studies included in the latter review ${ }^{(32)}$ provided evidence for a negative association between the consumption of breakfast cereals and BMI, which is in line with the negative association between breakfast consumption and BMI found in the present study including data over a 4-year period. Breakfast consumption has been linked to better overall nutrition ${ }^{(22,23,33)}$. Hence, children and adolescents eating breakfast more regularly might overall have more adequate food patterns, which might explain the steady significant inverse relationship with BMI $Z$-score ${ }^{(34)}$. The results of the present study indeed suggest that eating breakfast consistently (across a number of years) may be important for long-term management of body weight. The implications of our findings suggest that strategies designed to increase breakfast consumption in children and adolescents might be beneficial to reducing increases in BMI $Z$-score. On the other hand, it is also possible that children and adolescents with higher BMI $Z$-scores skip breakfast more often when trying to lose weight. In that case, increased BMI $Z$-scores are an antecedent instead of a consequence of breakfast consumption.

PA occurs over four dimensions: frequency, intensity, time and type ${ }^{(35)}$. In the present study, two (frequency and duration) of these four dimensions were measured. The results of the present study provide evidence that the frequency, but not duration, of sports participation plays a substantial role in weight management from childhood to adolescence. Hence, it might be more important for weight control to engage in sports activities more frequently for shorter periods of time instead of participating in such activities less frequently for a longer duration. Again, as the present study cannot be conclusive about causal relationships, lower grades of sports participation might be an antecedent or consequence of higher BMI $Z$-scores. Lower sports participation rates might result in higher BMI $Z$-scores. However, it is also possible that children with higher BMI are less likely to participate in sports activities due to their higher weight because of fears of teasing or because they are less athletic. A better understanding of the causal pathway is certainly needed. In addition, explained variances were low with only $1 \cdot 2 \%$ of the variance in BMI explained by frequency in sports participation. These low explained variances could explain why intervention studies are generally found to be ineffective in decreasing BMI among adolescents ${ }^{(36)}$.

The second purpose of the present study was to investigate the relationship of yearly changes in PA and dietary behaviours with yearly changes in BMI $Z$-score over a 4 -year period from childhood to adolescence. Results indicated that yearly decreases in fruit consumption, frequency of sports participation and hours of PE were all associated with higher increases in BMI $Z$-score. These findings might suggest that interventions aimed at preventing increases in BMI $Z$-score among children and adolescents could be effective if they are aimed at preventing decreases in fruit consumption and sports participation. Experimental studies, in which interventions are targeted at these behaviours in the transitional period from childhood to adolescence, are needed to confirm these findings. However, it is again possible that children and adolescents eat less fruit or drop out of organized sports due to increases in their body weight.

It has been recognized that $\mathrm{PE}$ should promote an active and healthy lifestyle with an emphasis on students' preparation for lifelong $\mathrm{PA}^{(37-39)}$. To more clearly focus PE on PA level goals, 'Healthy People 2010' recommends that PE be offered on a daily basis and that PE programmes make students perform moderate-to-vigorous PA during at least $50 \%$ of class time ${ }^{(40)}$. The results of the present study confirmed the importance of offering more PE classes at school, as decreases in hours of PE were related to increases in BMI $Z$-scores. These findings are in line with findings from another study showing that increases in BMI were smaller, as a result of an intervention offering more PE classes to children ${ }^{(41)}$.

The present study has some limitations. The first important limitation relates to the high attrition rates, especially during the transition period from childhood (leaving primary school) to adolescence (entering different secondary schools). However, analyses gave no indications for a particular subgroup with specific characteristics to drop out. A second important limitation relates to the use of selfreported measures of height and weight among children, which could have caused an underestimation of $\mathrm{BMI}^{(42)}$. Furthermore, behavioural measures were also self-reported and although validated questionnaires were used, this can be seen as a limitation of the study. Self-reported measures used to assess dietary intake of adolescents tend to result in reporting errors ${ }^{(43)}$ and PA self-reports often result in overestimation $^{(44)}$. In addition, although the prospective data finally give an indication of longitudinal associations, causality cannot be determined on the basis of the present data. For example, it is not possible to determine whether increased breakfast consumption causes lower BMI $Z$-scores or vice versa. An experimental study design would be needed to be conclusive about causal directions. 
The present study also has several strengths. In a recent review, several recommendations to move forward previous research were formulated ${ }^{(32)}$, which are met in the present study. By simultaneously measuring multiple behaviours, it was possible to account for possible confounders. Previous research was also advanced by using multiple waves of data and by employing a multi-level analytical design in a relatively large sample. The large sample sizes were needed to detect statistically significant relationships, as overweight develops due to small energy imbalances over time ${ }^{(35)}$. The analytical multi-level approach accounted for the withinpupil, between-pupil variation and for the correlation between repeated measurements on the same subjects. It furthermore allowed the inclusion of children with as few as one measurement.

\section{Acknowledgement}

Source of funding: The present study was supported by the Ghent University Research Foundation (Fund no. 011/105/ 04), the Flemish Research Foundation and the EU-funded HOPE project: 'Health-promotion through Obesity Prevention across Europe (the Commission of the European Communities, SP5A-CT-2006-044128). The study does not necessarily reflect the Commission's views and in no way anticipates the Commission's future policy in this area'. Conflicts of interest declaration: The authors have no conflict of interest. Authorship responsibilities: L.H. and I.D.B. performed most of the statistical analyses and the writing of the manuscript. C.V. and L.M. conducted and supervised most of the data collection. L.M. and I.D.B. supervised the study. All authors advised on study design, interpretation and critically reviewed and approved the manuscript.

\section{References}

1. World Health Organization (2004) Global strategy on diet, physical activity and health. http://www.who.int/ dietphysicalactivity/goals/en/index.html

2. Butte NF, Christiansen E \& Sorensen TIA (2007) Energy imbalance underlying the development of childhood obesity. Obesity 15, 3056-3066.

3. Hill J (2004) Physical activity and obesity. Lancet 363, 182.

4. Demory-Luce D, Morales M, Nicklas T et al. (2004) Changes in food group consumption patterns from childhood to young adulthood: the Bogalusa Heart Study. J Am Diet Assoc 104, 1684-1691.

5. Kimm SY, Glynn NW, Obarzanek E et al. (2005) Relation between the changes in physical activity and body-mass index during adolescence: a multicentre longitudinal study. Lancet 366, 301-307.

6. Lytle LA, Seifert S, Greenstein J et al. (2000) How do children's eating patterns and food choices change over time? Results from a cohort study. Am J Health Promot 14, 222-228.

7. World Health Organization (2004) Young People's Health in Context. Health Behavior in School-aged Children (HBSC) Study: International Report from 2001/2002 Survey: Health Policy for Children and Adolescents no. 4. Denmark: WHO.
8. Windle M, Grunbaum JA, Elliott M et al. (2004) Healthy passages - A multilevel, multimethod longitudinal study of adolescent health. Am J Prev Med 27, 164-172.

9. Driskell MM, Dyment S, Mauriello L et al. (2008) Relationships among multiple behaviors for childhood and adolescent obesity prevention. Prev Med 46, 209-215.

10. McCaffrey TA, Rennie KL, Kerr MA et al. (2008) Energy density of the diet and change in body fatness from childhood to adolescence: is there a relation? Am J Clin Nutr 87, 1230-1237.

11. Bisset S, Gauvin L, Potvin L et al. (2007) Association of body mass index and dietary restraint with changes in eating behaviour throughout late childhood and early adolescence: a 5-year study. Public Health Nutr 10, 780-789.

12. Ludwig DS, Peterson KE \& Gortmaker SL (2001) Relation between consumption of sugar-sweetened drinks and childhood obesity: a prospective, observational analysis. Lancet 357, 505-508.

13. Hill JO \& Peters JC (1998) Environmental contributions to the obesity epidemic. Science 280, 1371-1374.

14. Biddle SJ, Gorely T \& Stensel DJ (2004) Health-enhancing physical activity and sedentary behaviour in children and adolescents. J Sports Sci 22, 679-701.

15. Joshipura KJ, Ascherio A, Manson JE et al. (1999) Fruit and vegetable intake in relation to risk of ischemic stroke. JAMA 282, 1233-1239.

16. Johnson S (2004) Intake of fruit and vegetables and risk of stroke: an overview. Curr Opin Clin Nutr Metab Care 7 , $665-670$

17. Liu S, Manson JE, Lee IM et al. (2000) Fruit and vegetable intake and risk of cardiovascular disease: the Women's Health Study. Am J Clin Nutr 72, 922-928.

18. Ness AR \& Powles JW (1997) Fruit and vegetables, and cardiovascular disease: a review. Int J Epidemiol 26, 1-13.

19. Barton BA, Eldridge AL, Thompson D et al. (2005) The relationship of breakfast and cereal consumption to nutrient intake and body mass index: the National Heart, Lung, and Blood Institute Growth and Health Study. J Am Diet Assoc 105, 1383-1389.

20. Resnicow K (1991) The relationship between breakfast habits and plasma cholesterol levels in schoolchildren. J Sch Health 61, 81-85.

21. Nicklas TA, McQuarrie A, Fastnaught C et al. (2002) Efficiency of breakfast consumption patterns of ninth graders: nutrient-to-cost comparisons. J Am Diet Assoc 102, 226-233.

22. Gross SM, Bronner Y, Welch C et al. (2004) Breakfast and lunch meal skipping patterns among fourth-grade children from selected public schools in urban, suburban, and rural Maryland. J Am Diet Assoc 104, 420-423.

23. Nicklas TA, Myers L, Reger C et al. (1998) Impact of breakfast consumption on nutritional adequacy of the diets of young adults in Bogalusa, Louisiana: ethnic and gender contrasts. J Am Diet Assoc 98, 1432-1438.

24. Vereecken C \& Maes L (2003) A Belgian study on the reliability and relative validity of the health behaviour in school-aged children food frequency questionnaire. Public Health Nutr 6, 581-588.

25. Philippaerts RM, Matton L, Wijndaele K et al. (2006) Validity of a physical activity computer questionnaire in 12- to 18 year old boys and girls. Int J Sports Med 27, 131-136.

26. Haerens L, De Bourdeaudhuij I, Maes L et al. (2007) School based randomized controlled trial of a physical activity intervention among adolescents. J Adolesc Health 40, 258-265.

27. Haerens L, Deforche B, Vandelanotte C et al. (2007) Acceptability, feasibility and effectiveness of a computertailored physical activity intervention in adolescents. Patient Educ Couns 66, 303-310. 
28. Roelants M\& Hauspie R (2004) Growth Charts 2-20 Years, Flanders. http://www.vub.ac.be/groeicurven

29. Cole TJ (1990) The LMS method for constructing normalized growth standards. Eur J Clin Nutr 44, 45-60.

30. Cole TJ \& Green PJ (1992) Smoothing reference centile curves: the LMS method and penalized likelihood. Stat Med 11, 1305-1319.

31. Hollingshead AB (1957) Two-factor Index of Social Position. New Haven, CT: Yale University Press.

32. Newby PK (2009) Plant foods and plant-based diets: protective against childhood obesity? Am J Clin Nutr 89, S1572-S1587.

33. Albertson AM, Franko DL, Thompson D et al. (2007) Longitudinal patterns of breakfast eating in black and white adolescent girls. Obesity 15, 2282-2292.

34. Savige G, MacFarlane A, Ball K et al. (2007) Snacking behaviours of adolescents and their association with skipping meals. Int J Behav Nutr 4, 36.

35. Must A \& Tybor DJ (2005) Physical activity and sedentary behaviour: a review of longitudinal studies of weight and adiposity in youth. Int J Obes 29, Suppl. 2, S84-S96.

36. Harris KC, Kuramoto LK, Schulzer M \& Retallack JE (2009) Effect of school-based physical activity interventions on body mass index in children: a meta-analysis. CMAJ 180, 719-726.
37. Corbin CB (2002) Physical education as an agent of change. Quest 54, 182-195.

38. Sallis JF \& McKenzie TL (1991) Physical education role in public health. Res Q Exerc Sport 62, 124-137.

39. Stratton G (1997) Children's heart rate during British physical education lessons. J Teach Phys Educ 16, 357-367.

40. USDHH: United States Department of Health and Human Services (2000) Healthy People 2010: Understanding and Improving Health. Washington, DC: DHHS.

41. Sollerhed AC \& Ejlertsson G (2008) Physical benefits of expanded physical education in primary school: findings from a 3-year intervention study in Sweden. Scand J Med Sci Sports 18, 102-107.

42. Janssen I, Katzmarzyk PT, Boyce WF et al. (2005) Comparison of overweight and obesity prevalence in school-aged youth from 34 countries and their relationships with physical activity and dietary patterns. Obes Rev 6, 123-132.

43. Livingstone MB, Robson PJ \& Wallace JM (2004) Issues in dietary intake assessment of children and adolescents. Br J Nutr 92, Suppl. 2, S213-S222.

44. Wareham NJ \& Rennie KL (1998) The assessment of physical activity in individuals and populations: why try to be more precise about how physical activity is assessed? Int J Obes 22, Suppl. 2, S30-S38. 